\begin{tabular}{l} 
Sharif University of Technology \\
Scientia Iranica \\
SCIENTIA \\
IRAN \\
Thansactions A: Civil Engineering \\
\hline
\end{tabular}

\title{
Physical, mechanical, and durability properties of ternary blend concrete
}

\author{
G. Dhinakaran* and B. Sreekanth \\ School of Civil Engineering, SASTRA University, Thanjavur 613401, India.
}

Received 28 May 2016; received in revised form 6 December 2016; accepted 6 March 2017

\author{
KEYWORDS \\ Ternary blend; \\ Rice husk ash; \\ GGBFS; \\ Compressive strength; \\ Freeze and thaw; \\ Sorptivity; \\ Porosity; \\ Load deflection.
}

\begin{abstract}
Production of high-strength concrete by waste utilization attracts attention of more researchers everyday due to a number of benefits it brings to the present world. This paper, by replacing the cement in a considerable content, discusses the effect of such waste utilization on strength, durability, and structural behavior of high-strength concrete. Rice Husk Ash (RHA) (5 to 15\%) and Ground Granulated Blast Furnace Slag (GGBFS) (20 to $40 \%$ ) were used as mineral admixtures in three different percentages. The range of replacement of cement with this dual mixture was kept between $25 \%$ as minimum and $55 \%$ as maximum. Strength parameters, such as compression and flexure, and durability parameters, such as sorptivity, porosity, and freeze-thaw, were studied. All the tests were conducted as per ASTM standards. Ten combinations of ternary mix were tested and among them, the mix with 30\% GGBFS and 5\% RHA exhibited better performance in comparison with control concrete by compromising characteristic compressive strength to an extent of $5 \%$. It also yielded better performance in terms of durability characteristics. Hence, it was concluded that it could be possible to produce high-strength concrete with $35 \%$ replacement of cement either with $20 \%$ GGBFS and $15 \%$ RHA or $30 \%$ GGBFS and $5 \%$ RHA.

(C) 2018 Sharif University of Technology. All rights reserved.
\end{abstract}

\section{Introduction}

Rice Husk Ash (RHA) is recognized as a value added material due to its richness in silica content and potentiality of being used as pozzolanic material after calcination. Use of RHA leads the technology towards utilization of waste and reduction in cost. RHA has attracted the attention of many researchers due to its abundant availability as agricultural waste in many rice producing countries. The husk produced is either burnt or available as dumped waste material, which makes many environmental problems, such as pollution

*. Corresponding author. Tel.: 914362264101

E-mail addresses: gd@civil.sastra.edu (G. Dhinakaran); srikanthboga2009@gmail.com (B. Sreekanth)

doi: $10.24200 /$ sci. 2017.4210 of air and ground water. Landfills affect human health and expose environment to threat due to the emissions of biodegradation. They also cause ground water pollution by leachates and pose a high risk to ground water resource.

It is estimated that around $25 \%$ of RHA is generated either by burning of husk or milling of paddy. RHA is usually obtained by burning rice husk to a temperature of less than $700^{\circ} \mathrm{C}$ and is in amorphous state. It is further exposed to a temperature of above $850^{\circ} \mathrm{C}$ to convert to crystalline state. Another potential mineral admixture used as partial substitute for cement in the present work is Ground Granulated Blast Furnace Slag (GGBFS). GGBFS, a waste product obtained from steel industries, is rich in $\mathrm{SiO}_{2}$ and Calcium aluminates. Around 12 million tons of slag are produced by steel industries and 20 million tons of RHA are produced by rice industries [1]. 
Experiments have been conducted by using locally available materials and RHA has been used as a substitute for cement [2]. It was used as partial substitute for cement at different replacement levels from 10 to $30 \%$ to study the performance of high-strength concrete with a characteristic compressive strength of $70 \mathrm{MPa}$. From the results, it was concluded that RHA from 10 to $20 \%$ gave better results and optimum percentage fell within this range. Durability study was conducted on RHA based concrete through chloride ion penetration test. It was concluded that concrete with $\mathrm{RHA}$ range of $10 \%$ to $20 \%$ gave better results than the control concrete [3]. Effect of grinding of RHA obtained from ferro-cement furnace on rheological and mechanical behavior of concrete was investigated. From the results, it was understood that pozzolanic action of RHA was very effective and rich in amorphous silica. It was concluded that grinding of RHA made particles finer and provided higher strength than unground RHA and control concrete [4].

Possibility of using RHA as partial substitute for cement by varying its percentage from $10 \%$ to $25 \%$ for concrete with a characteristic compressive strength of $20 \mathrm{MPa}$ was studied [5]. In the results, no loss was observed either in workability or in strength up to $25 \%$ RHA as substitute for ordinary Portland cement. It was also noticed that changes in tensile and flexural strengths due to the substitution of RHA were insignificant. However, it was concluded that $10 \%$ RHA might be an optimum replacement for cement to make better structural concrete. Investigation into the effect of RHA on compressive strength by using RHA up to $30 \%$ was done. It was observed that use of RHA made concrete lightweight and better strength was attained at the later age of 90 days. It was concluded that the use of even $30 \%$ RHA, besides being cost-effective, had a tangible impact on strength [6].

Numerous research works have been carried out using the other well-known mineral admixture, namely, Ground Granulated Blast Furnace Slag (GGBFS). GGBFS was used in binary, ternary, and quaternary blend concrete to study the performance of concrete in hardened state. Parameters like effect of water-binder ratio, curing conditions, and age of concrete were studied [7-14]. Research works on GGBFS as partial replacement for cement in concrete revealed its suitability to act as a supplementary cementitious material imparting strength and corrosion resisting properties to concrete [15-19]. Certain researchers extensively worked on mechanical and durability properties of concrete with ground fly ash and slag, ultrafine slag, silica fume, and slag and found that ternary blend was a feasible solution in terms of strength, durability, and mitigation of environmental problems [20-24]. Since dumping of an industrial waste has become a major environmental problem in recent days, many works deal with construction or industrial wastes as mineral admixtures in concrete either as partial replacement for ordinary Portland cement or fine aggregate or coarse aggregate, since recycling is the best option for disposal. Effect of GGBFS on strength and durability of high-performance concrete was studied. It was concluded that replacement of cement with good percentage of GGBFS could be possible without compromising the quality of HPC [25].

\section{Experimental investigations}

\subsection{Materials}

The cement used in the present research work was Ordinary Portland Cement of ASTM Type I [26] and its specific gravity was found to be 3.15 . The average particle size was $45 \mu \mathrm{m}$. The other materials used were Rice Husk Ash (RHA) (with a particle size of $11 \mu \mathrm{m}$ ) and Ground Granulated Blast Furnace Slag (GGBFS) (with a particle size of $20 \mu \mathrm{m}$ ). The specific gravities of cement, RHA, and GGBFS were 3.15, 2.11, and 2.4, respectively. Rice husk was collected from a nearby rice company as dry inorganic material. The rich husk was then subjected to heating at a temperature of $500^{\circ} \mathrm{C}$ for a period of $4 \mathrm{hrs}$ in a muffle furnace for calcination. Figure 1 shows a photograph of rice husk ash. Initially, the ash appeared in dark black color, but after calcining, it changed to brown color. According to ASTM C618 [27], for a material to be classified as pozzolan, it should have $\mathrm{SiO}_{2}$ minimum of $70 \%$. The ASTM C618 specification is the most widely used one, since it covers the use of fly ash as a pozzolan or mineral admixture in concrete. The three classes of pozzolan are Class N, Class F, and Class C; the rich husk ash used here is classified as Class $\mathrm{N}$ pozzolan. To determine the chemical composition and pozzolanic nature of bamboo leaf ash, X-ray fluorescence test was

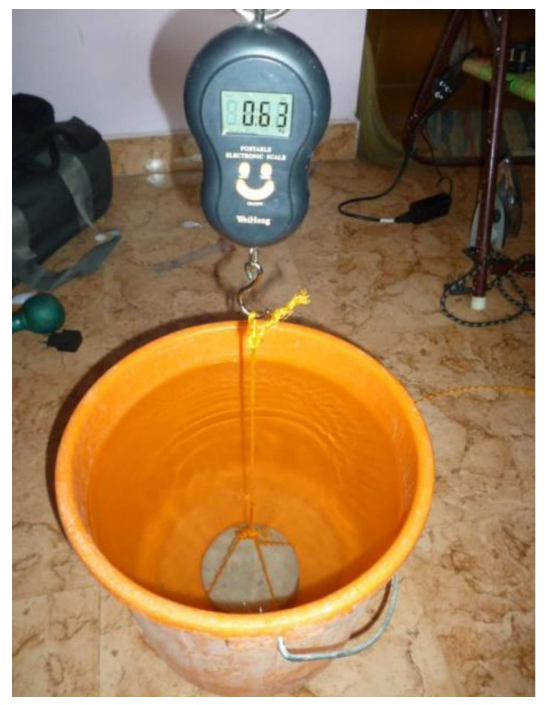

Figure 1. Details of the voids test (as per ASTM C642). 
Table 1. Chemical composition of cement, RHA, and GGBFS.

\begin{tabular}{|c|c|c|c|}
\hline \multirow{2}{*}{ Formula } & \multicolumn{3}{|c|}{ Concentration (\%) } \\
\hline & Cement & RHA & GGBFS \\
\hline $\mathrm{CaO}$ & 68.05 & 1.00 & 34.85 \\
\hline $\mathrm{SiO}_{2}$ & 25.91 & 94.34 & 34.01 \\
\hline $\mathrm{Al}_{2} \mathrm{O}_{3}$ & 5.85 & 0.35 & 16.62 \\
\hline $\mathrm{MgO}$ & 0.07 & 0.59 & 9.11 \\
\hline $\mathrm{Fe}_{2} \mathrm{O}_{3}$ & 0.12 & 0.17 & 1.71 \\
\hline $\mathrm{SO}_{3}$ & - & 0.36 & 1.55 \\
\hline $\mathrm{TiO}_{2}$ & - & 0.02 & 0.69 \\
\hline $\mathrm{Na}_{2} \mathrm{O}$ & - & 0.22 & 0.48 \\
\hline $\mathrm{K}_{2} \mathrm{O}$ & - & 1.96 & 0.46 \\
\hline $\mathrm{MnO}$ & - & 0.05 & 0.27 \\
\hline $\mathrm{BaO}$ & - & - & 0.10 \\
\hline $\mathrm{P}_{2} \mathrm{O}_{5}$ & - & 0.88 & 0.04 \\
\hline $\mathrm{SrO}$ & - & - & 0.04 \\
\hline $\mathrm{Cl}$ & - & - & 0.03 \\
\hline $\mathrm{ZrO}_{2}$ & - & $27 \mathrm{ppm}$ & 0.03 \\
\hline $\mathrm{As}_{2} \mathrm{O}_{3}$ & - & - & $37 \mathrm{ppm}$ \\
\hline
\end{tabular}

carried out using an XRF-analyzer. X-ray fluorescence test samples were used in the determination of major and trace elements in solids.

Chemical composition of cement, RHA, and GGBFS is tabulated in Table 1 . The fine aggregate used in the present work was natural river sand. Maximum size of coarse aggregate was limited to $12.5 \mathrm{~mm}$. Specific gravity of sand and coarse aggregate was found to be 2.65. Specific gravity of coarse aggregate was determined by using wire basket method as per ASTM C127 [28]. Sulphonated naphthalene polymer based super plasticizer, called Conplast SP 430 G8, was used to improve workability of the fresh concrete. The addition of super plasticizer reduced the $w / c$ ratio and the workability was verified with slump cone test according to ASTM C143 [29].

\subsection{Evaluation of Pozzolanic Activity of RHA}

Pozzolanic activity of RHA was studied by doing test on strength activity index with Portland cement as per ASTM C311 [30]. In the test mixtures, ordinary Portland cement was replaced with different percentages of RHA ( $5 \%$ to $20 \%$ with an increment rate of $5 \%$ ). The ratio of cement to sand and cement + RHA to sand was taken as 1:2.75 and quantity of water was taken as an amount that gave the required consistency. After the specimens were cast, they were kept at $23^{\circ} \mathrm{C}$ for one day in accordance with ASTM C 311 to complete the final setting process and reach hardened state. Then, the specimens were removed from the moulds and cured in saturated lime water as per ASTM C109 [31]. ASTM C618 permits testing of compressive strength in either 7 or 28 days; thus, specimens were tested at the age of 28 days. Compressive strengths of all the six specimens in each replacement percentage and strength activity indices were determined from the compressive strength ratio of test mixture to control mixture. It was inferred that strength activity index or pozzolanic activity index of specimens with rice husk ash was above $80 \%$ that of control specimen at the age of 28 days, fulfilling the requirements as pozzolan to be used in concrete as per ASTM standard. By the addition of RHA beyond $15 \%$, strength activity index showed reverse trend and gave an idea of maximum percentage of pozzolanic admixture to be used.

\subsection{Mix design}

In the present work, a high-strength concrete with characteristic compressive strength of $50 \mathrm{MPa}$ was used. ACI 211.1 [32] was used to perform the mix design and the resulting mix proportion was 1:0.76:2.61 (Binder: Fine aggregate: Coarse aggregate) with water to binder ratio of 0.38 . The addition of high range water reducer reduced the $w / c$ ratio from 0.38 to 0.35 and the workability was verified through slump cone test according to ASTM C143. There were 10 different mix combinations tested in the present work to attain an optimum mix for ternary blend. The details of mix combinations are given in Table 2. From the table, one can see that minimum percentage of cement replacement was $25 \%$ and the maximum was $55 \%$.

\subsection{Designation of mixes}

In the present work, ten mixes were used to study the effect of ternary blend. All the ten mixes were designated with letters as given below for better understanding of readers:

A- C100S0R0: Control concrete

B- C75S20R5: Ternary blend (cement 75\% + GGBFS $20 \%+$ RHA $5 \%$ )

Table 2. Ternary blend mix combinations.

\begin{tabular}{cccc}
\hline Mix & $\begin{array}{c}\text { Cement } \\
(\boldsymbol{\%})\end{array}$ & $\begin{array}{c}\text { GGBFS } \\
(\boldsymbol{\%})\end{array}$ & $\begin{array}{c}\text { RHA } \\
(\boldsymbol{\%})\end{array}$ \\
\hline A & 100 & - & - \\
B & 75 & 20 & 5 \\
C & 70 & 20 & 10 \\
D & 65 & 20 & 15 \\
E & 65 & 30 & 5 \\
F & 60 & 30 & 10 \\
G & 55 & 30 & 15 \\
H & 55 & 40 & 5 \\
I & 50 & 40 & 10 \\
J & 45 & 40 & 15 \\
\hline
\end{tabular}


C- C70S20R10: Ternary blend (cement $70 \%+$ GGBFS $20 \%$ + RHA 10\%)

D- C65S20R15: Ternary blend (cement 65\% + GGBFS $20 \%$ + RHA 15\%)

E- C65S30R5: Ternary blend (cement 65\% + GGBFS $30 \%+$ RHA $5 \%)$

F- C60S30R10: Ternary blend (cement 60\% + GGBFS 30\% + RHA 10\%)

G- C55S30R15: Ternary blend (cement 55\% + GGBFS 30\% + RHA 15\%)

H- C55S40R5: Ternary blend (cement 55\% + GGBFS $40 \%+$ RHA $5 \%)$

I- C50S40R10: Ternary blend (cement 50\% + GGBFS $40 \%$ + RHA 10\%)

J- C45S40R15: Ternary blend (cement $45 \%+$ GGBFS $40 \%$ + RHA 15\%)

Henceforth, the above mixes will be referred to by their designation.

\subsection{Specimens}

Concrete specimens of the size $100 \mathrm{~mm} \times 100 \mathrm{~mm} \times$ $100 \mathrm{~mm}$ cubes were cast as per BS 1881 [33] to test the compressive strength of concrete. Then, the specimens were cured for two different ages, namely, 14 days and 28 days, to assess the ternary blend performance at different stages of hydration. Specimens of $100 \mathrm{~mm}$ height and $50 \mathrm{~mm}$ diameter were cast to assess the durability characteristics, such as voids as per ASTM C642 [34], sorptivity as per ASTM C1585 [35], and prisms of $100 \mathrm{~mm} \times 100 \mathrm{~mm} \times 275 \mathrm{~mm}$ for freeze and thaw as per ASTM C666 [36]. Beams of $100 \mathrm{~mm} \times$ $150 \mathrm{~mm} \times 1200 \mathrm{~mm}$ were cast to study load-deflection characteristics.

\section{Methods}

\subsection{Compressive strength}

Specimens for testing of compressive strength from ten different combinations of mixes were cast with the size of $100 \mathrm{~mm} \times 100 \mathrm{~mm} \times 100 \mathrm{~mm}$, cured for the designated periods, and subsequently tested as per the guidelines of BS 1881. After the desired period of curing, specimens were tested in computerized Universal Testing Machine (UTM) of $1000 \mathrm{kN}$ capacity. A total number of 60 specimens were cast and tested for compressive strength. The rate of loading applied was $200 \mathrm{kN} / \mathrm{min}$.

\subsection{Voids and water absorption}

Volume of permeable pores was assessed by the method prescribed by ASTM C642. This test method was used to determine density, absorption percentage, and percent voids in hardened concrete. As per this method, the volume of specimen should not be less than $350 \mathrm{~cm}^{3}$. After being removed from the mould, the specimen was kept at a temperature of $110^{\circ} \mathrm{C}$ for $24 \mathrm{~h}$ in hot air oven. Then, it was kept at a temperature of $25^{\circ} \mathrm{C}$ and the mass was determined. Afterwards, it was immersed in water at $21^{\circ} \mathrm{C}$ for $48 \mathrm{~h}$ and the mass was taken. Then, the specimen was boiled in tap water for $5 \mathrm{~h}$ and cooled for $14 \mathrm{~h}$ to a final temperature of $25^{\circ} \mathrm{C}$. Finally, the specimen was suspended into water and the mass was determined. Substituting the values of mass in different conditions in the formula, the volume of voids and water absorption percentage were determined (see Figure 1).

\subsection{Sorptivity}

The resistance against capillary suction was determined as per ASTM C1585. In this method, cylindrical specimens were prepared and placed in the environmental chamber at a temperature of $50^{\circ} \mathrm{C}$ for 3 days. After the 3 days, they were placed inside a sealable container. Then, the specimens were kept at $23^{\circ} \mathrm{C}$ for 15 days before the start of the absorption procedure. All the surfaces were coated with epoxy resin, except for the bottom surface. Bottom surface was exposed to water. Then, the mass of the specimens was noted at different intervals of time (see Figure 2).

\subsection{Freeze and thaw}

Test method for freeze and thaw consists in the determination of the resistance of concrete specimens to rapidly repeated cycles of freezing and thawing in the laboratory by two different procedures (ASTM C666):

- Procedure A: Rapid freezing and thawing in water;

- Procedure B: Rapid freezing in air and thawing in water.

In the present research work, rapid freezing in air and thawing in water was followed. Prisms specimen of $100 \mathrm{~mm} \times 100 \mathrm{~mm} \times 275 \mathrm{~mm}$ was prepared. The moulded beam specimens were cured for 14 days prior to testing and the hardened concrete was moisture conditioned by immersing in saturated lime water for 2 days. Before starting the freeze and thaw cycles,

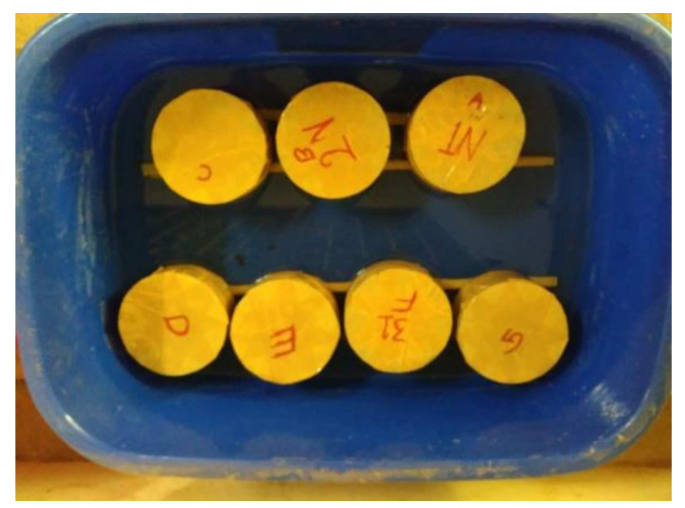

Figure 2. Specimens of curing for sorptivity test (as per ASTM C1585). 
the mass, average length, and cross section dimensions of the concrete specimen were noted (by the tolerance required in test method as per ASTM C215) [37]. The nominal freezing and thawing cycle for this test method consist in alternatively lowering the temperature of specimens from 4 to $-18^{\circ} \mathrm{C}$ for 180 minutes and raising it from -18 to $4^{\circ} \mathrm{C}$ for 30 minutes (called one cycle). Transverse frequency of the specimens before starting the cycles was determined and continued for the subsequent intervals of cycles. Freezing and thawing tests were started by placing the specimens in the thawing water at the beginning of the thawing phase of the cycle. Then, the specimens were removed from the apparatus, in a thawed condition, at intervals not exceeding 20 cycles of exposure to the freezing and thawing cycles. In case of the transverse mode, the specimen's supports were at $0.224 \mathrm{~L}$ from the edge of the specimen. The vibration was gradually increased until the maximum value was reached, which was the resonance transverse frequency for the specimen. The resonance occurred when the driving frequency was a fraction of the fundamental frequency. The dynamic moduli for the concrete specimens were determined according to ASTM C215 (see Figures 3 and 4).

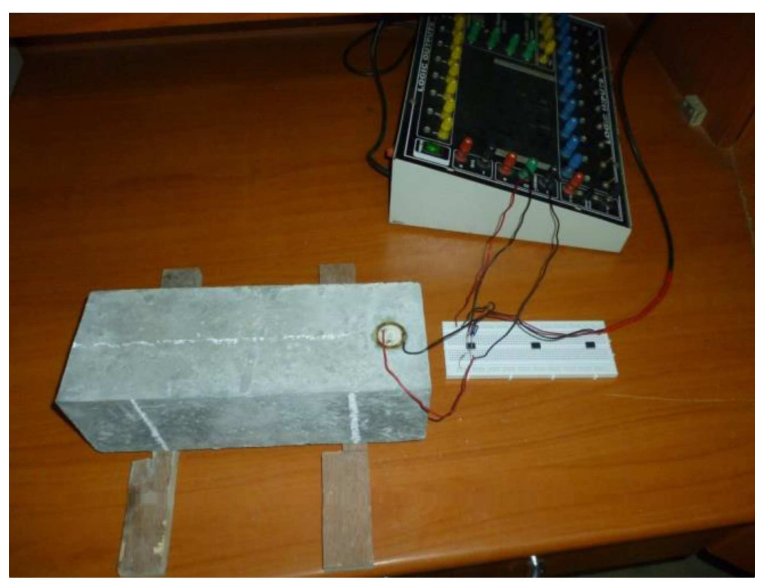

Figure 3. Specimen arrangements for measurement of transverse frequency.

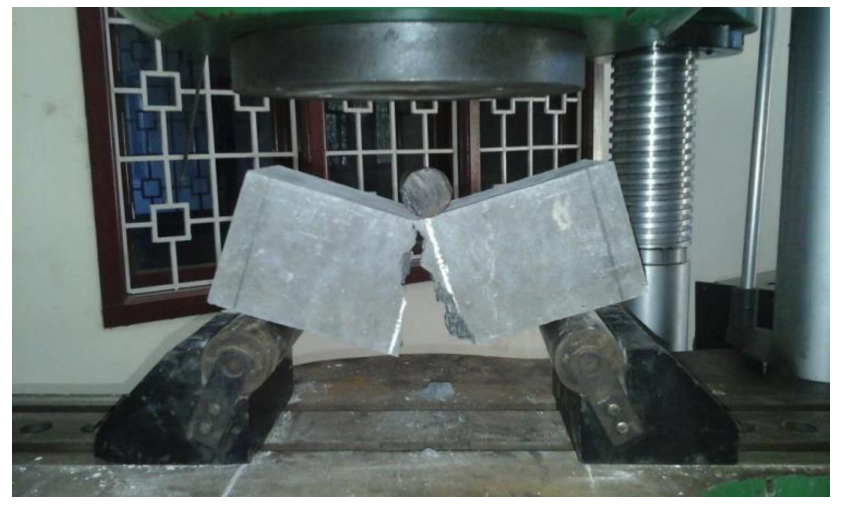

Figure 4. Specimen tested for its modulus of rupture.

\subsection{Flexural behavior}

For finding flexural behavior, tests were carried out on $100 \mathrm{~mm} \times 150 \mathrm{~mm} \times 1200 \mathrm{~mm}$ beam prototypes at the age of 28 days using $1000 \mathrm{kN}$ capacity flexural strength testing machine. The test setup included two-point loading system by which the loads were transferred equally to the two points using a spreader beam and two rollers. The gauge length between the loading points was $333 \mathrm{~mm}$ (one third from the support). An offset of $100 \mathrm{~mm}$ was available on either side of the beam from the supports. Dial gauges were placed at the bottom of the beam to find mid-span deflection. The load was applied at the rate of $10 \mathrm{kN} / \mathrm{min}$. Automatic data acquisition system was used to record the load and displacement, which was connected to the computer. Two bars with $10 \mathrm{~mm}$ diameter were utilized in the tension zone and two bars with $8 \mathrm{~mm}$ diameter were utilized in the compression zone as longitudinal reinforcement. Transverse reinforcement was made with a bar of $8 \mathrm{~mm}$ diameter at a spacing of $125 \mathrm{~mm}$ near supports, which increased towards the center (see Figure 5).

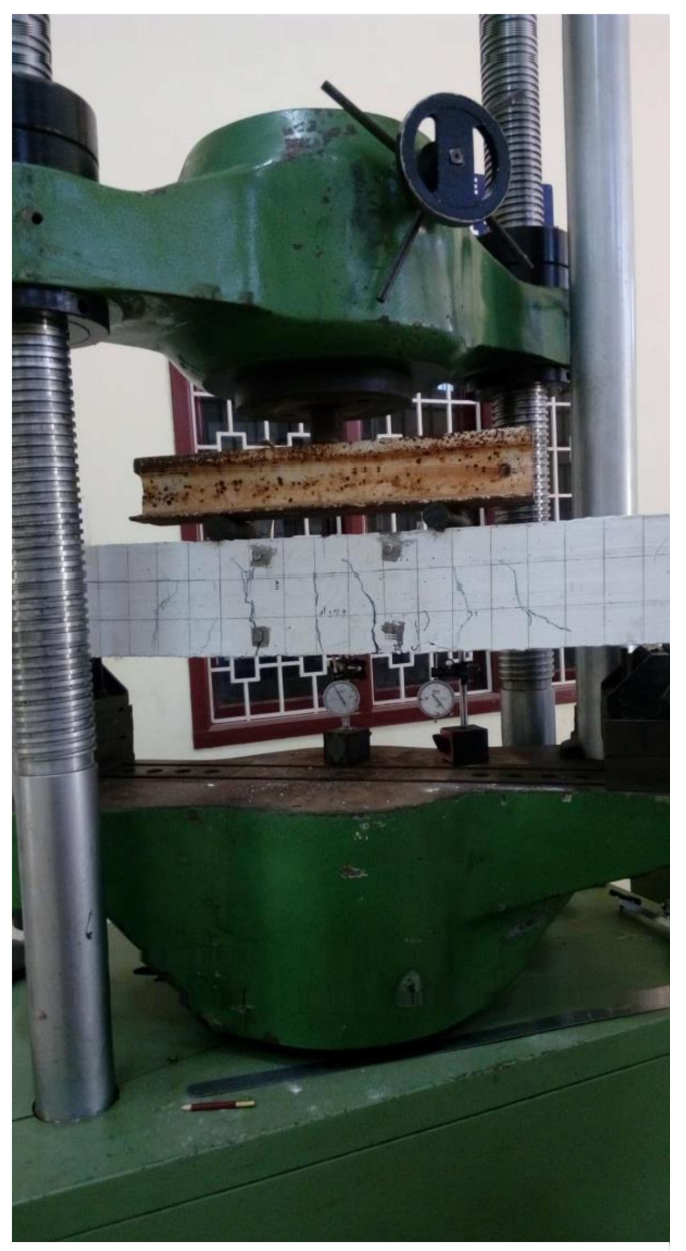

Figure 5. Beam specimen tested for its structural behavior. 


\section{Results and discussion}

\subsection{General}

It is important to note the following points before proceeding to the detailed discussion of results of the present work. Among ten different combinations studied (one control mix and nine ternary mixes) for assessing compressive strength, four mixes were chosen for durability study based on their performance (one control mix and three ternary mixes). Again, for studying structural behavior, only one optimum mix from ternary combination (taken from strength and durability performance) and one control mix for the purpose of comparison were taken.

\subsection{Mass}

The variation of mass of specimens due to the effect of ternary mix was studied by taking the mass of the respective specimens after 28 days of curing. It was observed that the mass of specimens was linearly reduced with mix combinations from A to J. Since mix A had no mineral admixture, it had higher mass among all the specimens $(2.75 \mathrm{~kg})$. This value decreased linearly to $2.47 \mathrm{~kg}$ for the ternary mix J. It could be due to two reasons; one the lower specific gravity of the mineral admixtures (RHA and GGBFS) used for replacement with cement and the other increase in replacement percentage (see Figure 6).

\subsection{Compressive strength}

The variation of compressive strength for different percentage replacements of cement with rice husk ash and ground granulated blast furnace slag at two different ages of concrete is depicted in Figure 7 to show the effect of age on ternary blend concrete. The strength of concrete with rice husk ash and slag at the age of 14 days was found to be higher in ternary combinations $\mathrm{D}, \mathrm{E}, \mathrm{I}$, and J than in the control concrete. It could be due to optimum filling of voids of mineral admixture added. In both mixes $\mathrm{D}$ and $\mathrm{E}$, the percentage of replacement of cement was maintained at $35 \%$, and GGBFS and RHA could accelerate gaining the strength at the age of 14 days. Similar trend was observed for

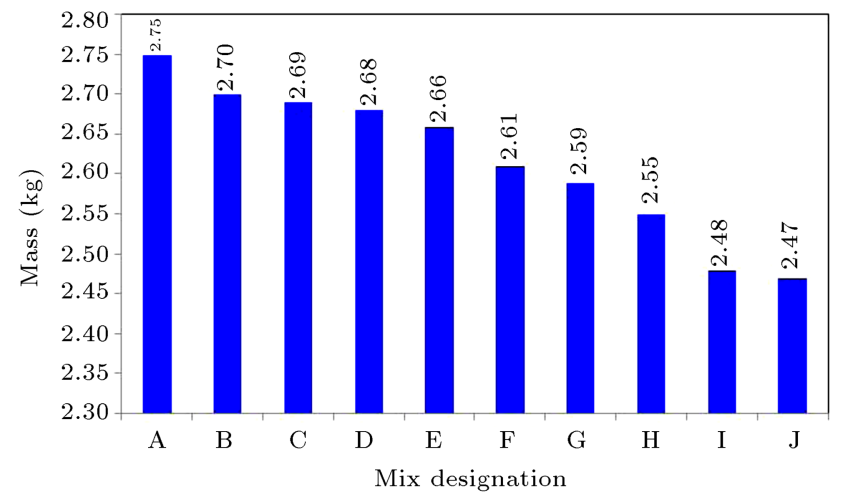

Figure 6. Mass variations of ternary mix combinations .

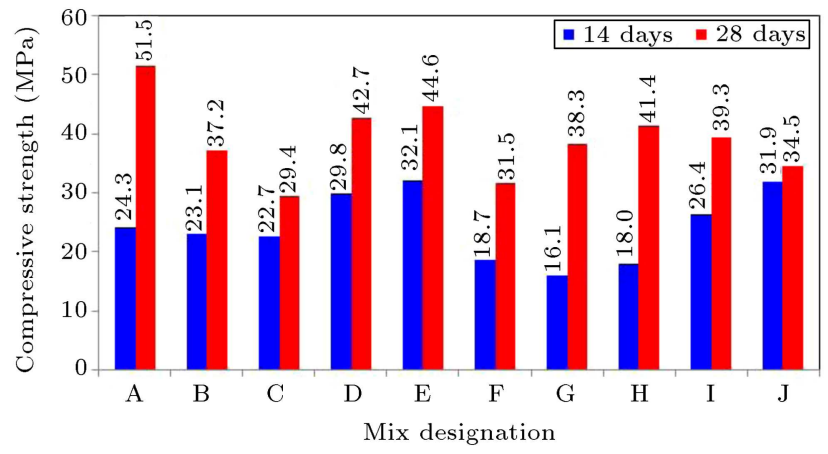

Figure 7. Compressive strength of ternary mix combinations.

mixes I and J, in which GGBFS was maintained at $40 \%$ and RHA values were $10 \%$ and $15 \%$. It could be due to high volume replacement of cement with mineral admixtures. At the age of 28 days, mixes D and $E$ yielded better results than all the other ternary mixes did. Moreover, the performance of mixes B and $\mathrm{C}$ was poorer than that of mixes $\mathrm{D}$ and $\mathrm{E}$. The reason could be inadequate quantity of cement replacement with GGBFS. In general, the minimum replacement of cement, especially with GGBFS, was maintained at $30 \%$ to have better results. Quantities less than this were not able to react effectively and were insufficient. This was one reason why the strength results were found to be less for these mixes.

However, the compressive strength of control concrete was higher than that of all the ternary mixes. It is worthy to note that both the mixes $\mathrm{D}$ and $\mathrm{E}$ had cement replacement of $35 \%$. Though only $20 \%$ slag was used in mix D (i.e., less than $30 \%$ ), role of $15 \%$ RHA was predominant and, hence, strength was maintained. Among the two ternary mixes D and $\mathrm{E}$, mix $\mathrm{E}$ gave better strength. Hence, mix $\mathrm{E}$ could be the optimum one among 9 different ternary mixes used. The compressive strength of mix E was $10 \%$ lower than the characteristic compressive strength of concrete, while for the mixes $D$ and $H$, this value was $14 \%$ and $17 \%$ lower, respectively. In the case of mix $\mathrm{H}$, cement was replaced to an extent of $45 \%$, which led to $17 \%$ reduction in strength. From the literature, it is inferred that for the concrete with ternary blend, the reduction in strength is from $10 \%$ to $15 \%$. Mixes $\mathrm{D}$ and $\mathrm{E}$ gave the characteristic compressive strengths of $42.7 \mathrm{MPa}$ and 44.6 $\mathrm{MPa}$, respectively. Hence it is suggested that, if concrete produced by replacing $35 \%$ of cement with GGBFS and RHA, mix design to be done for $50 \mathrm{MPa}$ to get characteristic strength of 40 $\mathrm{MPa}$ in the field.

\subsection{Evaluation of water absorption and voids in hardened concrete}

The water absorption and voids values were calculated as per the guidelines of ASTM C642-13. From the results (refer to Table 3 ), the water absorption per- 
Table 3. Calculations of water absorption and voids (as per ASTM C642).

\begin{tabular}{|c|c|c|c|c|c|}
\hline \multirow{2}{*}{ Description } & \multirow{2}{*}{$\begin{array}{c}\text { Formula/ } \\
\text { designation }\end{array}$} & \multicolumn{4}{|c|}{ Mix designation } \\
\hline & & $\mathbf{A}$ & $\mathbf{D}$ & $\mathbf{E}$ & $\mathbf{H}$ \\
\hline Mass of oven-dried sample in air $(\mathrm{g})$ & A & 1107 & 1028 & 1041 & 1039 \\
\hline Mass of surface-dried sample in air after immersion $(\mathrm{g})$ & $\mathrm{B}$ & 1136 & 1063 & 1068 & 1069 \\
\hline Mass of surface-dried sample in air after immersion and boiling $(\mathrm{g})$ & $\mathrm{C}$ & 1145 & 1071 & 1076 & 1075 \\
\hline Apparent mass of sample in water after immersion and boiling $(\mathrm{g})$ & $\mathrm{D}$ & 686 & 637 & 646 & 646 \\
\hline Absorption after immersion $(\%)$ & {$[(\mathrm{B}-\mathrm{A}) / \mathrm{A}] \times 100$} & 2.62 & 3.40 & 2.59 & 2.89 \\
\hline Absorption after immersion and boiling (\%) & {$[(\mathrm{C}-\mathrm{A}) / \mathrm{A}] \times 100$} & 3.43 & 4.18 & 3.36 & 3.46 \\
\hline Bulk density, dry (g/cc) & $g_{1}=[\mathrm{A} /(\mathrm{C}-\mathrm{D})] \times \rho^{*}$ & 2.41 & 2.37 & 2.42 & 2.42 \\
\hline Bulk density after immersion (g/cc) & {$[\mathrm{B} /(\mathrm{C}-\mathrm{D})] \times \rho$} & 2.47 & 2.45 & 2.48 & 2.49 \\
\hline Bulk density after immersion and boiling (g/cc) & {$[\mathrm{C} /(\mathrm{C}-\mathrm{D})] \times \rho$} & 2.49 & 2.47 & 2.50 & 2.51 \\
\hline Apparent density (g/cc) & $g_{2}=[\mathrm{A} /(\mathrm{A}-\mathrm{D})] \times \rho$ & 2.63 & 2.63 & 2.64 & 2.64 \\
\hline Volume of permeable pore space (voids) (\%) & {$\left[\left(g_{2}-g_{1}\right) / g_{2}\right] \times 100$} & 8.28 & 9.91 & 8.14 & 8.39 \\
\hline
\end{tabular}

$* \rho=$ density of water in $\mathrm{g} / \mathrm{cc}$

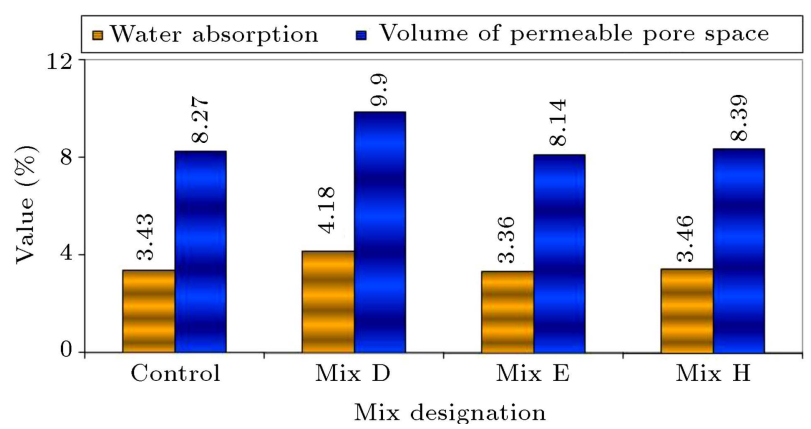

Figure 8. Water absorption and voids of ternary mix combinations.

centage values were found to be $3.43 \%, 4.18 \%, 3.36 \%$, and $3.46 \%$ for the mixes $\mathrm{A}, \mathrm{D}, \mathrm{E}$, and $\mathrm{H}$, respectively (refer to Figure 8). The amount of water absorption percentage was found to be higher for mix $\mathrm{D}$, which was also more than that for the control concrete. However, this value decreased for mix $E$ and showed a reverse trend for mix $\mathrm{H}$. It could be due to higher volume of RHA in the case of mix D. For the mixes E and $H$, the volume of GGBFS was more and the voids were filled with RHA. In mix D, the volume of RHA was much higher and, hence, water absorption percentage was found to be more. It is worthy to note that the amount of water absorption for concrete and volume of permeable pore space for combination $\mathrm{E}$ were less than those for control concrete. The rate of reduction in water absorption percentage for combination $\mathrm{E}$ was found to be $2.05 \%$ with respect to control concrete. Similar trend was observed in volume of permeable pores, since both water absorption percentage and volume of permeable pores were directly proportional. Hence, it was evident that the added rice husk ash and slag served as micro fillers in the voids or pores of concrete and modified the microstructure, resulting in a denser concrete (see Figure 8).

\subsection{Evaluation of Sorptivity characteristics}

The resistance against capillary suction due to the addition of rice husk ash was studied by conducting sorptivity test as per ASTM C1585-13. The initial absorption by capillary suction for control concrete was found to be $2.54 \mathrm{~mm}$ (average of sorption values in the first 6 hours). These values for the concrete with ternary blend combinations $\mathrm{D}, \mathrm{E}$, and $\mathrm{H}$ were $2.18 \mathrm{~mm}$, $1.78 \mathrm{~mm}$, and $2.03 \mathrm{~mm}$, respectively. From the results for all percentages of addition of rice husk ash and slag, the sorption values were found to be less than that for control concrete and the maximum reduction was observed in the concrete with combination $\mathrm{E}$ (C65S30R5). For the concrete with combinations E and $H$, the sorption values were found to be less than the value for control concrete. In a similar way, the values of secondary absorption by capillary suction were calculated for the averages from 6 hours to 9 days. The capillary suction for control concrete was found to be $1.79 \mathrm{~mm}$ and this value for concrete with ternary blend combinations $\mathrm{D}, \mathrm{E}$, and $\mathrm{H}$ was $1.78 \mathrm{~mm}$, $1.02 \mathrm{~mm}$, and $1.28 \mathrm{~mm}$, respectively. In the results of initial absorption, $14 \%, 30 \%$, and $20 \%$ reductions were observed in concrete with ternary blend combinations $\mathrm{D}, \mathrm{E}$, and $\mathrm{H}$, respectively, in comparison with the control concrete. The incremental values during secondary absorption were $1 \%, 43 \%$, and $28 \%$ for concrete with ternary blend combinations $\mathrm{D}, \mathrm{E}$, and $\mathrm{H}$, respectively, in comparison with control concrete. In comparison of initial sorption and secondary sorption, sorption at the initial stage was found to be more aggressive irrespective of concrete, whether it was control or with ternary blend combinations. The $R^{2}$ values of control concrete and concrete with ternary blend combinations $\mathrm{D}, \mathrm{E}$, and $\mathrm{H}$ were found to be $0.85,0.82,0.89$, and 0.90 , respectively. Since all the values of $R^{2}$ exceeded 


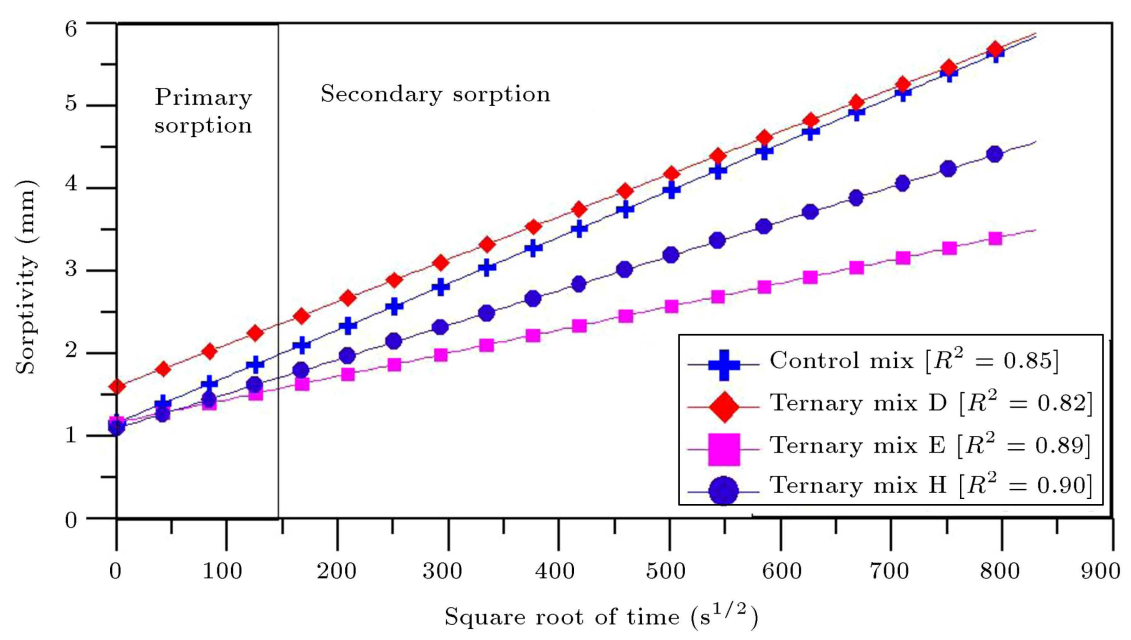

Figure 9. Sorptivity of ternary mix combinations.

0.80 , the goodness of fit was found to match well (see Figure 9).

\subsection{Evaluation of freeze and thaw characteristics}

The evaluation of freeze and thaw due to addition of rice husk ash and slag was performed as per ASTM C666-03. There was a change in weight of the specimen when the it was exposed to continuous freeze and thaw cycles. After completion of 20 freeze and thaw cycles, there was no significant effect on the dimensions of cross section and length. Pre-test and post-test of flexural strength (Modulus of Rupture) were carried out for the specimens before and after the completion of freeze and thaw cycles. It was observed that the specimen exposed to freeze and thaw cycles experienced reduction in modulus of rupture. Flexural strength of the mix $\mathrm{E}$ was the highest among all the other values. In the comparison of freeze and thaw of various mixes between 0 cycles and 10 cycles, $10 \%$ reduction for control concrete, $8 \%$ for mix D, $7.5 \%$ for mix E, and $6 \%$ for mix $\mathrm{H}$ of ternary combinations were observed. These values, after 20 cycles, were found to be $20 \%$ for control concrete, $15 \%$ for mix D, $13.5 \%$ for mix $\mathrm{E}$, and $16.5 \%$ for mix $\mathrm{H}$ of ternary combinations. From the results, ternary mixes were found to be better than control mix irrespective of number of cycles. The values for modulus of rupture were reduced to an extent of $50 \%$ when freeze-thaw cycles were doubled from 10 to 20 for all the ternary mixes, except for mix $H$. Mix $\mathrm{H}$ performed well in lower numbers of freeze and thaw cycles and showed a reverse trend by increase in cycles (could be due to high volume replacement of ordinary Portland cement with RHA and GGBFS) (see Figure 10).

\subsection{Flexural behavior}

Mix D of ternary blend with $30 \%$ GGBFS and 5\% RHA consistently performed well in terms of both strength

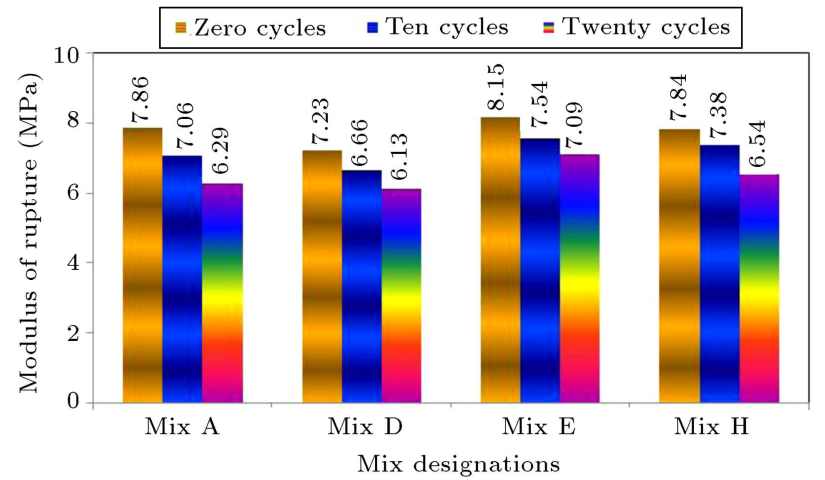

Figure 10. Modulus of rupture of ternary mix combinations after freeze and thaw cycles.

and durability characteristics. Hence, this optimum mix was chosen for casting a beam to study the flexural behavior and the results were compared with results of control concrete. The load deflection curves were drawn for the beams cast with control concrete and mix E of ternary blend $(65 \%$ cement $+30 \%$ GGBFS $+5 \%$ RHA), and the results are depicted in Figure 11. For the assessment of load deflection behavior, two beams in each category were cast and tested. Average values of two beams were calculated in the results. The first crack in the beams by the load was observed at $32.45 \mathrm{kN}$ in control concrete, whereas in the ternary mix E, it was observed at $30.6 \mathrm{kN}$. The load at the first crack gave an idea of internal resistance by the respective beam at initial level of loading. It was observed that the first crack developed a bit earlier in the case of beams cast with ternary mix. The ultimate loads carried by the beams were $60 \mathrm{kN}$ for control concrete and $57 \mathrm{kN}$ for mix $\mathrm{E}$ with ternary blend. Both first crack load and ultimate load of mix $\mathrm{E}$ of ternary blend were $5 \%$ less than those of the control concrete; a value which was insignificant. Hence, it is suggested that concrete with ternary blend (mix E) with $30 \%$ GGBFS and 5\% RHA can be used in 


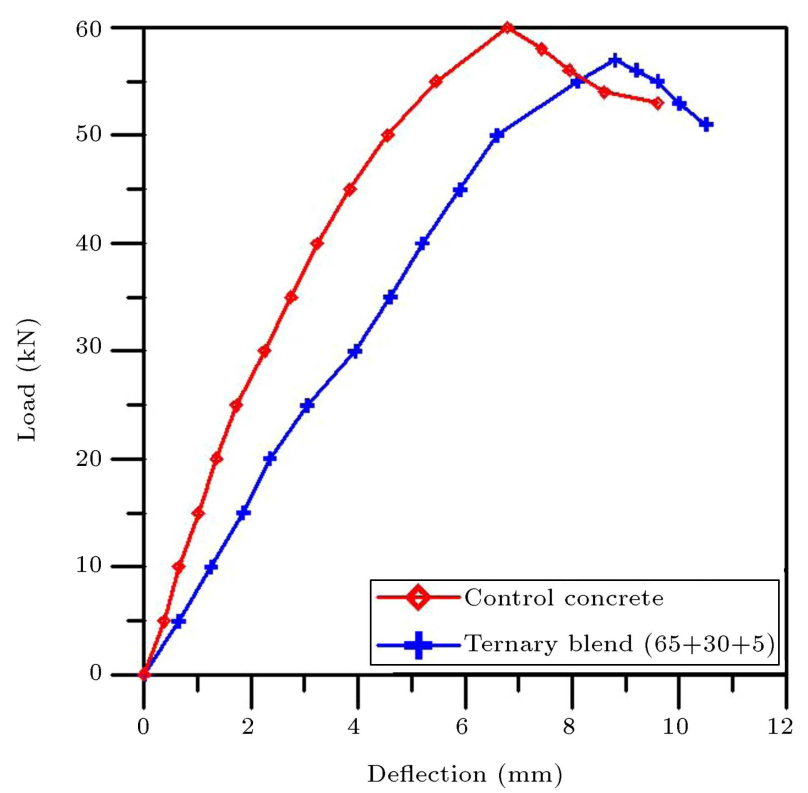

Figure 11. Load deflection characteristics of control and ternary mixes.

the place where normal concrete is required without compromising strength and durability characteristics.

\section{Conclusions}

From the detailed experimental investigations conducted into concrete with rice husk ash and ground granulated blast furnace slag for its strength, durability, and structural behavior, the following conclusions were reached:

1. Replacement of $35 \%$ cement with rice husk ash and ground granulated blast furnace slag (mixes D and E) reduced only $10 \%$ of characteristic compressive strength and led to better durability characteristics;

2. Replacement of $45 \%$ cement with rice husk ash and ground granulated blast furnace slag (mix H) reduced $20 \%$ of characteristic compressive strength and led to better durability characteristics;

3. By replacing a sizeable quantity of Ternary mixes (35\% to $45 \%$ RHA and GGBFS) with cement, the requirement for cement and, in turn, the production of greenhouse gases would be minimized;

4. No significant difference was observed in ultimate load carrying capacity and load deflection characteristics between the optimum ternary mix E and control concrete; hence, the suitability of ternary mix E for structural concrete was ensured;

5. From the experiments conducted, ternary mix E was found to be the optimum mix in terms of strength, durability, and flexural behavior;

6. It is suggested that, if ternary mixes D (C65S20R15), E (C65S30R5), and H (C55S40R5) are used in the field and the required concrete strength is $40 \mathrm{MPa}$, mix design should be done for $50 \mathrm{MPa}$.

\section{Acknowledgements}

The authors would like to thank the Vice Chancellor of Sastra University for having provided experimental facilities in the School of Civil Engineering to do this research work and for the continuous support and encouragement throughout this research work.

\section{References}

1. Madurwar, M.V., Ralegaonkar, R.V., and Mandavgane, S.A. "Application of agro-waste for sustainable construction materials: A review", Constr. Build. Mater., 38, pp. 872-878 (2013).

2. Ismail, M.S. and Waliuddin, A.M. "The effect of rice husk ash on high strength Concrete", Constr. Build. Mater., 10(I), pp. 521-526 (1996).

3. Reddy, D.V. and Marcelina Alvarez, B.S. "Marine durability characteristics of rice husk ash-modified reinforced concrete", Fourth LACCEI International Latin American and Caribbean conference for Engineering and Technology (LACCET'2006) "Breaking Frontiers and Barriers in Engineering: Education, Research and Practice" 21-23 June 2006, Mayagüez, Puerto Rico (2006).

4. Habeeb, G.A. and Mahmud, H.B. "Study on properties of rice husk ash and its use as cement replacement material", Mater. Res., 13(2), pp. 185-190 (2010).

5. Akeke, G.A., Ephraim, M.E., Akobo, I.Z.S., and Ukpata, J.O. "Structural properties of rice husk ash concrete", Int. J. Eng. Appl. Sci., 3(3), pp. 57-62 (2013).

6. Samuel, A.A. and Emmanuel, S. "Fracture behavior of concrete with rice husk ash replacement under uniaxial compressive loading", Res. J. Eng. Appl. Sci., 2(2), pp. 132-136 (2013).

7. Montes, P., Theodore, W., and Castellanos, B.F. "Interactive effects of fly ash and CNI on corrosion of reinforced high-performance concrete", Mater. Struct., 39(2), pp. 201-210 (2006).

8. Pan, Z.H., Hiromi, F., and Wee, T.H. "Preparation of high performance foamed concrete from cement, sand and mineral admixtures", Mater. Sci. Edn., 22(2), pp. 295-298 (2007).

9. Guneyisi, E. and Gesoglu, M. "A study on durability properties of high-performance concretes incorporating high replacement levels of slag", Mater. Struct., 41(3), pp. 479-493 (2008).

10. Cordeiro, G.C., Filho, R.D.T., and Rego Fairbairn, E.M. "Use of ultra fine rice husk ash with high-carbon content as pozzolan in high performance concrete", Mater. Struct., 42(7), pp. 983-992 (2009). 
11. Chinnaraju, K., Subramanian, K., and Senthilkumar, S.R.R. "Strength properties of HPC using binary, ternary and quaternary cementitious blends", Struct. Conc., 11(4), pp. 191-198 (2010).

12. Mazanec, O., Lowke, D., and Schie, P. "Mixing of high performance concrete: effect of concrete composition and mixing intensity on mixing time", Mater. Struct., 43(7), pp. 357-365 (2010).

13. Lü, J.F., Guan, H., Zhao, W.X., and Ba, H.J. "Compressive strength and permeability of highperformance concrete", Mater. Sci. Edn., 26(1), pp. 137-141 (2011).

14. Hwang, S.D., Khayat, K.H., and Youssef, D. "Effect of moist curing and use of lightweight sand on characteristics of high-performance concrete", Mater. Struct., 46(1-2), pp. 35-46 (2013).

15. Atis, C.D. and Bilim, C. "Wet and dry cured compressive strength of concrete containing ground granulated blast-furnace slag", Build. Environ., 42(8), pp. 30603065 (2007).

16. Teng, S., Lim, T.Y.D., and Divsholi, B.S. "Durability and mechanical properties of high strength concrete incorporating ultra fine ground granulated blast-furnace slag", Constr. Build. Mater., 40, pp. 875-881 (2013).

17. Shannag, M.J. "High strength concrete containing natural pozzolan and silica fume", Cem. Conc. Compos., 22(6), pp. 399-406 (2000).

18. Appa Rao, G. "Development of strength with age of mortars containing silica fume", Cem. Conc. Res., 31(8), pp. 1141-1146 (2001).

19. Kartikeyan, B., Sumanth, K., Harshavardhan, G., Rajasekharareddy, A., and Dhinakaran, G. "Microstructure analysis and strength properties of concrete with nano SiO2", Int. J. ChemTech Res., 6(5), pp. 30043013 (2014).

20. Bleszynski, R., Doug Hooton, R., Michael Thomas, D.A., and Rogers, C.A. "Durability of ternary blend concrete with silica fume and blast-furnace slag: laboratory and outdoor exposure site studies", ACI Mater. J., 99, pp. 499-508 (2002).

21. Elahi, A., Basheer, P.A.M., Nanukuttan, S.V., and Khan, Q.U.Z. "Mechanical and durability properties of high performance concrete containing supplementary cementitious materials", Constr. Build. Mater., 24, pp. 292-299 (2002).

22. Kevin Smith, M., Andrea Schokker, J., and Paul Tikalsky, J. "Performance of supplementary cementitious materials in concrete resistivity and corrosion monitoring evaluations", ACI Mater. J., 101(5), pp. 385-390 (2004).

23. Sengul, O. and Tasdemir, M.A. "Compressive strength and rapid chloride permeability of concretes with ground fly ash and slag", J. Mater. Civ. Eng., 21(9), pp. 494-501 (2009).

24. Susanto, T., Lim, T.Y.D., and Divsho, B.S. "Durability and mechanical properties of high strength con- crete incorporating ultra fine ground granulated blastfurnace slag", Constr. Build. Mater., 40, pp. 875-881 (2013).

25. Vijayasarathy, R. and Dhinakaran, G. "Strength and durability characteristics of GGBFS based HPC", Asian J. Appl. Sci., 7(4), pp. 224-231 (2014).

26. ASTM C 150/C150M-12, Standard Specification for Portland Cement, American Society for Testing and Materials, ASTM International, West Conshohocken, PA, USA (2012).

27. ASTM C618, Standard Specification for Coal Fly Ash and Raw or Calcined Natural Pozzolan for Use in Concrete, American Society for Testing and Materials, ASTM International, West Conshohocken, PA, USA (2008).

28. ASTM C 127-12, Standard Test Method for Density, Relative Density (Specific Gravity) and Absorption of Coarse Aggregate, American Society for Testing and Materials, ASTM International, West Conshohocken, PA, USA (2012).

29. ASTM C 143-12, Standard Test Method for Slump of Hydraulic-Cement Concrete, American Society for Testing and Materials, ASTM International, West Conshohocken, PA, USA (2012).

30. ASTM C311-05, Standard Test Methods for Sampling and Testing Fly Ash or Natural Pozzolans for Use in Portland Cement Concrete, American Society for Testing and Materials, ASTM International, West Conshohocken, PA, USA (2005).

31. ASTM C109/C109M, Test Method for Compressive Strength of Hydraulic Cement Mortar, American Society for Testing and Materials, ASTM International, West Conshohocken, PA, USA (1993).

32. ACI 211.1, Standard Practice for Selecting Proportions for Normal, Heavyweight and Mass Concrete, American Concrete Institute, Farmington Hills, MI, USA (1991).

33. BS 1881-1983, Method for Determination of Water Absorption, British Standard Testing Concrete Part 122, British Standards Institution, 2 Park Street London W1 A 2BS (1983).

34. ASTM C 642-13, Standard Test Method for Density, Absorption, and Voids in Hardened Concrete, American Society for Testing and Materials, ASTM International, West Conshohocken, PA, USA (2013).

35. ASTM C 1585-13, Standard Test Method for Measurement of Rate of Absorption of Water by HydraulicCement Concretes, American Society for Testing and Materials, ASTM International, West Conshohocken, PA, USA (2013).

36. ASTM C666 -03, Standard Test Method for Resistance of Concrete to Rapid Freezing and Thawing, American Society for Testing and Materials, ASTM International, West Conshohocken, PA, USA (2003).

37. ASTM C215-14, Standard Test Method for Fundamental Transverse Frequency of Concrete Specimen, American Society for Testing and Materials, ASTM International, West Conshohocken, PA, USA (2014). 


\section{Biographies}

Govindasamy Dhinakaran is a Professor in the School of Civil Engineering at SASTRA University, Thanjavur, India. He received his BE degree in Civil Engineering from Bharathidasan University in 1988, ME degree from National Institute of Technology in 1990, and $\mathrm{PhD}$ degree in Offshore Structures from Indian Institute of Technology Madras, in 2003. He has published more than 50 papers in peer reviewed journals at international level, 20 papers at national level, and 20 papers at international conferences. He has completed two research projects funded by Government of India. He has guided $7 \mathrm{PhD}$ scholars and is currently guiding $2 \mathrm{PhD}$ scholars. He is a Fellow in Institution of Engineers (India) and Life Member of Indian Geotechnical Society. He is also serving as reviewer for international journals like ACI Materials, Construction and Building Materials, Ocean Engineering, etc. His research interests include sustainable concrete materials, admixed concrete, and materials in aggressive environment.

Boga Sreekanth has speciality in the area of Structural Engineering. He received his BE degree in Civil Engineering from Sri Venkateswara University, Tirupati, and MTech in Structural Engineering from SASTRA University, Thanjavur, in 2014 and 2016, respectively. At present, he is working as structural engineer and running a consultancy firm in Hyderabad, India. He is involved in planning, analysis, and design in the area of Structural Engineering. His research interests include strength and durability characteristics of concrete made with mineral admixtures. 